\title{
Analysis of power supply possibilities through lithium batteries connected to the AC grid
}

\author{
R. Dufo López ${ }^{1}$, S. Sanz Ortega ${ }^{1}$, J.S. Artal Sevil ${ }^{1}$, M. Astaneh², J. Lujano Rojas ${ }^{1}$, J.A. Domínguez \\ Navarro $^{1}$ and J.L. Bernal Agustín ${ }^{1}$ \\ ${ }^{1}$ Department of Electrical Engineering \\ Escuela de Ingeniería y Arquitectura. Universidad de Zaragoza \\ C/ María de Luna, 3. 50018 Zaragoza \\ Phone number:+0034 876555124, e-mail: rdufo@ unizar.es, sanortso@gmail.com, jsartal@unizar.es, \\ lujano.juan@gmail.com, jadona@unizar.es, jlbernal@unizar.es

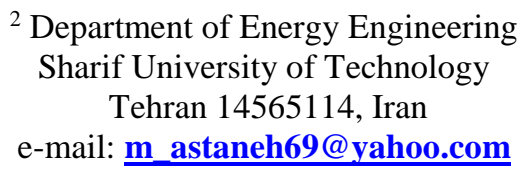

\begin{abstract}
In this paper we present a techno-economical analysis of grid-connected lithium batteries. A time-of-use (TOU) electricity tariff will be considered so that batteries can be charged during hours of low electricity price and discharged during hours of high electricity price. Four cases will be studied, depending if it is allowed or not to inject electricity to the AC grid during the discharge of the batteries and also depending if there is photovoltaic generator. Case 1: batteries discharge just to meet the load (no electricity injection to the grid); Case 2: Batteries discharge meet the load and also inject to the grid; Case 3: Photovoltaic generator + case 1; Case 4: Photovoltaic generator + case 2. In all the cases, the Net Present Cost (NPC) is calculated. All the cases are compared to the base case of supplying electricity without batteries. The Li-ion battery cost must be reduced at least $70 \%$ to be profitable in this applications. In that case, if selling electricity to the AC grid is allowed and the selling price is $70 \%$ of the price of the electricity, the battery system can be a good option, with or without PV generator.
\end{abstract}

\section{Key words}

Grid-connected li-ion battery, net present cost, timeof-use electricity tariff, photovoltaic generator

\section{Introduction}

Nowadays, the most suitable storage technologies to be used in residential, commercial, or industrial buildings are Li-ion, Ni-Cd, or lead-acid batteries, on account of their maturity, high efficiency, low maintenance, and low danger [1]. Li-ion batteries are in general secure and their lifetime is much higher than traditional lead-acid batteries or Ni-Cd (although their price is higher, the price per $\mathrm{kWh}$ cycled is lower).
There are different technologies of Li-ion batteries. The most of the commercial batteries to be used in gridconnected applications are lithium iron phosphate (LiFePO4) and and lithium nickel manganese cobalt oxide $\left(\mathrm{LiNiMnCoO}_{2}\right.$ or $\left.\mathrm{NMC}\right)$ [2].

Under time-of-use (TOU) electricity tariffs, it can be economically profitable to charge the battery during hours when the electricity price is low and discharge it during hours when the electricity price is high, supplying the load and avoiding to buy expensive electricity to the $\mathrm{AC}$ grid. If it is allowed to sell electricity to the AC grid, the profitability can be even higher. If the difference of the high and low price is high, the battery storage can be economically a good option. However, it depends on the price of the battery bank, the number of cycles to failure (that is, the energy that can by cycled by the battery during its whole lifetime), the round trip efficiency, the difference on electricity price (high-low) and its expected inflation $[1,3]$. The best procedure to know if it is profitable is to calculate the Net Present Cost (NPC) of the system, which includes all the costs during the lifetime of the system (acquisition cost of the components, replacement, operation and maintenance and cost of electricity purchased from the grid). The NPC of the system with batteries will be compared to the NPC of the system without batteries and we will see if this option is economically profitable. For all the cases the system lifetime will be considered as 25 years (same as the lifetime of the photovoltaic generator, in the case it is present in the system; battey lifetime depend on the charge/discharge cycles). 
The system includes (Fig. 1) the battery bank, rectifier (battery charger), inverter and control unit. Some commercial systems are built all in one.

In some cases, a photovoltaic (PV) generator can be considered, so that the energy produced by the PV during hours when the electricity from the grid is cheap is stored and when electricity from the grid is expensive the energy stored is consumed by the load (and, if it is allowed, it can also be injected and sold to the AC grid).

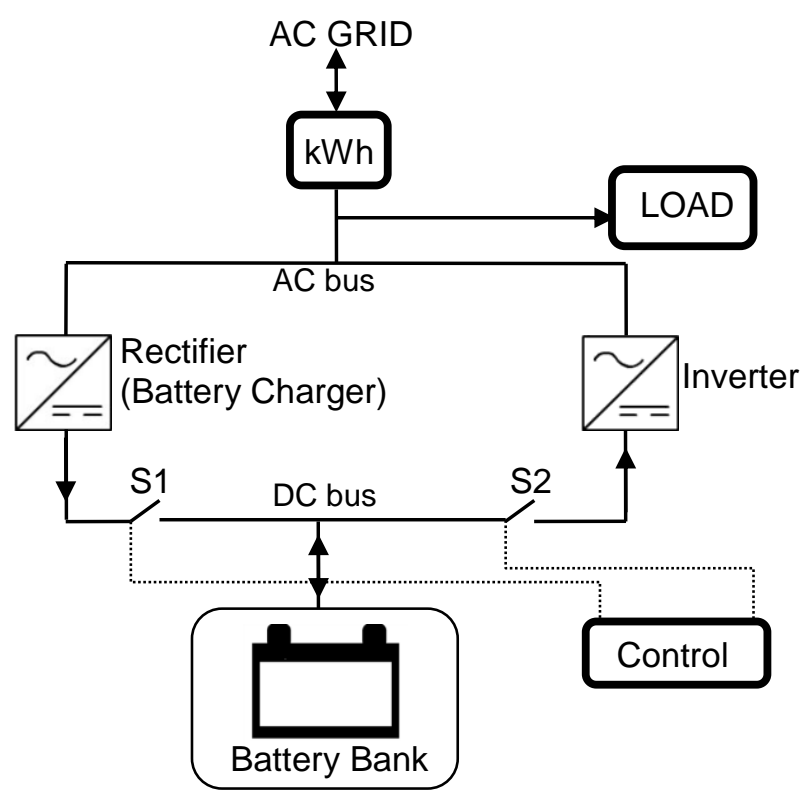

Fig. 1. Grid-connected battery system

The techno-economical evaluation will be performed by iHOGA software [4].

\section{Types of systems considered}

The base case (Case 0) is the case without batteries, that is, the case of a typical consumer, with a typical connection to the AC grid and using the most profitable tariff (usually it is a tariff with same price for all the hours, not a TOU tariff).

The base case will be compared to 4 different cases that include batteries. The cases with batteries will be the following:

Case 1: Batteries are charged by the electricity of the AC grid during hours when electricity price is low (valley). During peak hours (hours electricity price is high), the batteries are discharged to supply the load. In general this case is allowed by the different regulatory laws of the different countries, if there is a device that ensures there is no injection of electricity to the AC grid.

Case 2: Batteries are charged by the electricity of the AC grid during hours when electricity price is low (valley). During peak hours (hours electricity price is high), the batteries are discharged to supply the load and also to inject energy to the AC grid (that is sold to the electricity retailer). It is allowed by some regulatory laws as the injection to the $\mathrm{AC}$ grid cannot be dangerous to the maintenance personnel if there is a islanding protection (grid-connected inverters include this protection).

Case 3: Same strategy as in case 1 but the system includes PV generator.

Case 4: Same strategy as in case 2 but the system includes PV generator.

Selling electricity injection to the grid in Spain now is not allowed. However, we will consider these cases as it could be allowed in a near future.

\section{Cases of study}

The cases of study are detailed in the reference [5]. The data used are summarized in the following subsections.

\section{A. Load demand}

In all the cases we will consider a typical household load of 3 persons with the profile of Fig. 2, and a total load of the year of 2,800 kWh (average daily load of 7.67 $\mathrm{kWh} /$ day) [6].

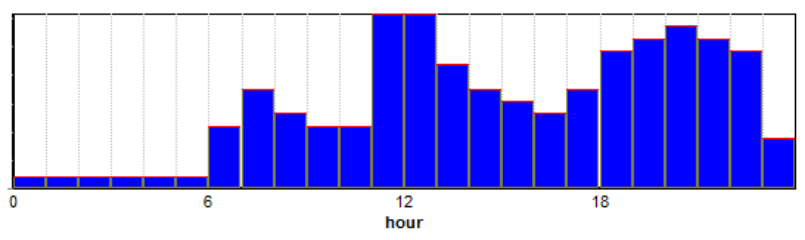

Fig. 2. Load profile

\section{B. Electricity tariffs considered}

Fort the case 0 (base case, without batteries) we will consider a typical household tariff, for all the hours the same price. The tariff used is "Tempo" of Endesa retailer. In our case, with a hired power of $3.45 \mathrm{~kW}$ the anual cost of power availability is $189.69 € /$ year and the cost of the energy is $0.178966 € / \mathrm{kWh}$ (included electricity taxes and VAT).

For the rest of the cases (with batteries) we have selected the "Supervalle" tariff of Endesa retailer, which is the one with highest difference between high (peak) and low (valley) electricity price in Spain. In our case, with a hired power of $3.45 \mathrm{~kW}$ the anual cost for power availability is $156.42 € /$ year and the cost of the energy is $0.196 € / \mathrm{kWh}$ in peak hours, $0.089 € / \mathrm{kWh}$ in medium hours (called "valle") and $0.066 € / \mathrm{kWh}$ in valley hours (called "supervalle"), included electricity taxes and VAT.

In cases 2 and 4 a price for the electricity sold to the AC grid is needed. As it is not known because in Spain it is not allowed, we have considered different cases: 30\%, $50 \%$ or $70 \%$ of the price of the electricity tariff when electricity is injected to the AC grid (in peak hours). 


\section{Inflation and interest rate}

In order to calculate the NPC, economical parameters must be settled. A general inflation of $2 \%$ anual has been considered for all the costs except for the cost of electricy purchased from the AC grid (for this we have considered three scenarios, with $1 \%, 2 \%$ and $3 \%$ anual inflation; same values have been considered for the electricity sold to the AC grid (cases 2 and 4). The interest rate has been considered as $4 \%$ annual.

\section{Batteries considered in the study}

Two comercial batteries are considered in the study (Table I), Tesla Poweball 2 DC and LG Chem RESU3.3.

Table I. - Batteries considered

\begin{tabular}{|l|r|r|}
\hline Manufacturer & \multicolumn{1}{|c|}{ Tesla } & LG Chem \\
\hline Model & $\begin{array}{c}\text { Powerball } \\
\text { 2 DC }\end{array}$ & RESU3.3 \\
\hline Nominal Capacity (Ah) & 38.57 & 63 \\
\hline Nominal Voltage $(\mathrm{V})$ & 350 & 48 \\
\hline Enenrgy Capacity $(\mathrm{kWh})$ & 13.5 & 3.0 \\
\hline Acquisition cost $(€)$ & 6100 & 3400 \\
\hline Specific cost $(€ / \mathrm{kWh})$ & 452 & 1124 \\
\hline O\&M cost $(€ /$ yr) & 30 & 30 \\
\hline Max. DOD $(\%)$ & 90 & 90 \\
\hline Cycles to failure (max. DOD) & 3200 & 3200 \\
\hline Round trip efficiency $(\%)$ & 91.8 & 95 \\
\hline
\end{tabular}

Table 2 show the inverter-charger to be used by the Tesla battery (SMA Sunny Boy Storage) and by the LG Chem battery (STECA Solarix PI 1200 with a charge controller P Tarom 4140 of 149 A and a generic charger of $3000 \mathrm{~W}$ ).

Table II. - Inverter-chargers

\begin{tabular}{|c|c|c|}
\hline Manufacturer & SMA & STECA \\
\hline Model & $\begin{array}{l}\text { Sunny Boy } \\
\text { Storage }\end{array}$ & Solarix PI 1200 \\
\hline Nominal power (VA) & 2500 & 900 \\
\hline VDC mín (V) & 100 & 42 \\
\hline VDC máx (V) & 500 & 64 \\
\hline Acquisition cost $(€)$ & 1590 & 650 \\
\hline Charger & Included & No \\
\hline Battery controller & $\begin{array}{l}\text { Included } \\
\text { MPPT }\end{array}$ & No \\
\hline $\begin{array}{l}\text { Expected lifetime } \\
\text { (years) }\end{array}$ & 10 & 10 \\
\hline Charging efficiency $(\%)$ & 98 & 100 \\
\hline Extra Battery controller & & $\begin{array}{c}\text { Tarom } 4140 \\
(149 \mathrm{~A})\end{array}$ \\
\hline Extra Charger & & $\begin{array}{c}\text { Generic (3000 } \\
W)\end{array}$ \\
\hline
\end{tabular}

A PV generator of up to $5.6 \mathrm{kWp}$ in Zaragoza (Spain) has been considered in cases 3 and 4. It is composed of 20 PV panels of $280 \mathrm{Wp}$, with its own grid invertir. The total cost of the PV generator is 7,000 $€$ and its lifetime is 25 years. The panels are oriented with an azimuth of $0^{\circ}$ (south) and slope of $35^{\circ}$ (optimal for grid-connected PV in Zaragoza) or with two-axis tracking. The

\section{Results}

The cases of study are detailed in the reference [5]. The results are summarized in the following subsections.

\section{A. Case 0}

The results of case 0 (without batteries) are shown in Table III. NPC depends on the annual electricity price expected inflation for the 25 years of study.

Table III. - Results of case 0 (without batteries)

\begin{tabular}{|c|c|}
\hline $\begin{array}{c}\text { Electricity Price expected annual } \\
\text { inflation }\end{array}$ & NPC $(€)$ \\
\hline $1 \%$ & 12218 \\
\hline $2 \%$ & 13711 \\
\hline $3 \%$ & 15445 \\
\hline
\end{tabular}

\section{B. Case 1}

The results of case 1 are shown in Fig. 3. The NPC is shown vs the electricity price expected annual inflation. The base case (case 0 , section A) is compared to 6 subcases of case 1 , depending on the battery used (Tesla or LG) and its price: original price, $50 \%$ off $(50 \%$ discount of the original price) or $70 \%$ off $(70 \%$ discount of the original price). The cases of $50 \%$ off and $70 \%$ off can be achieved in some years, if prices continue dropping down.

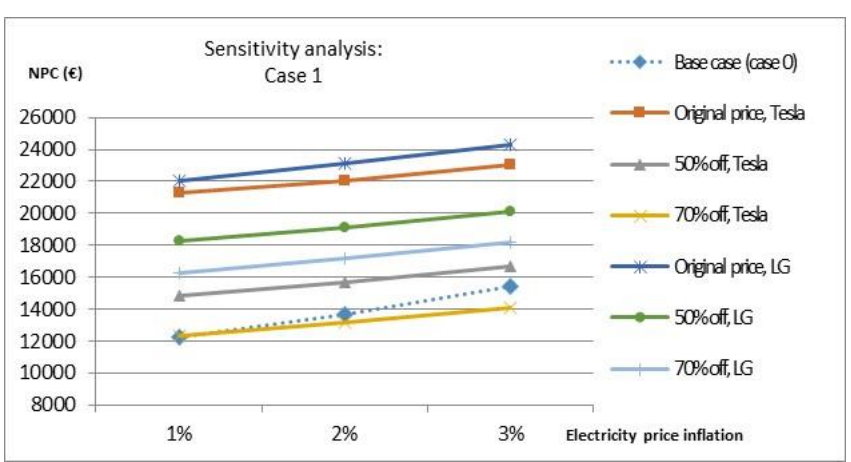

Fig. 3. Results of case 1 . NPC vs electricity price inflation.

Fig. 3 shows that, considering the current prices of batteries (original price, Tesla; original price, LG) the NPC is much higher than the NPC of the case 0 , so the battery system is not profitable. The cost of the battery, 
including the replacement during the years is higher than the savings in purchasing electricity during the peak hours.

Only in the case of Tesala with $70 \%$ discount of original price (that is, the battery price is only $30 \%$ of the price shown in Table I) and $1 \%$ expected electricity price inflation the NPC is similar to case 0 (Fig. 3). In the rest of the cases, the NPC is higher than in case 0 , so this kind of systems are not profitable.

A simulation screen of iHOGA software is shown in Fig. 4, where the charge (blue) and discharge (light brown) of the battery bank, the State of Charge (SOC, red), the load (grey) and the electricity bought to the AC grid (light blue, thin line) are shown.

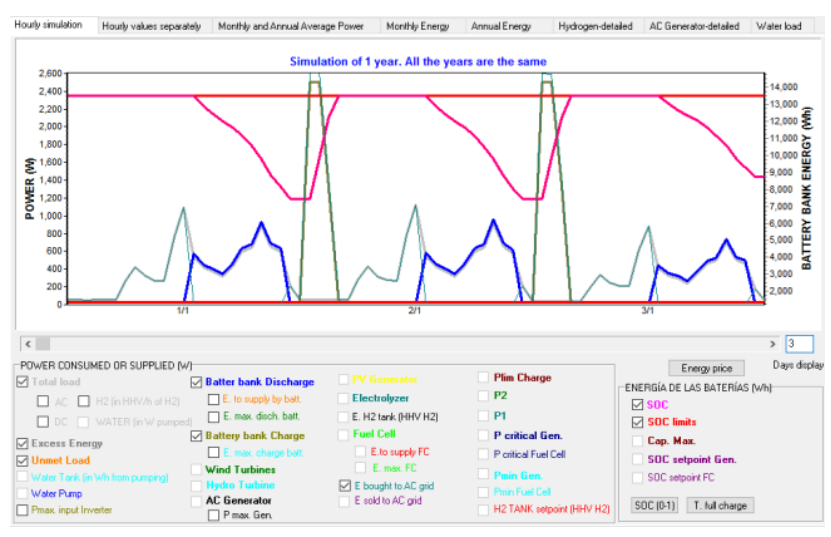

Fig. 4. Simulation of a specific case, iHOGA software.

\section{Case 2}

Fig. 5 shows the results of case 2 . We compare case 0 with 6 subcases of case 2, all of them use Tesla battery but the price is original, $50 \%$ off or $70 \%$ off of the original price and the selling price is $30 \%, 50 \%$ or $70 \%$ of the electricity tariff $(0,3 \mathrm{Ec}, 0,5 \mathrm{Ec}$ or $0,7 \mathrm{Ec})$.

For $1 \%$ and $2 \%$ of electricity price inflation, the battery system is profitable only in the case of battery price with discount of $70 \%$ and selling the electricity at $70 \%$ of the purchasing cost. In the case of $3 \%$ of electricity price inflation, there are more profitable cases.

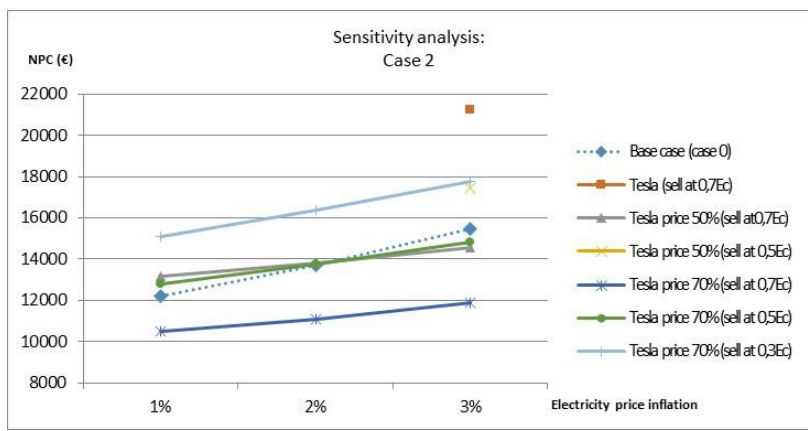

Fig. 5. Results of case 2 . NPC vs electricity price inflation.

\section{Case 3}

Fig. 6 shows the results of case 3 for a location of Zaragoza, Spain. The subcases are for different price discount for the batteries. Only the case of battery price with discount of $70 \%$ is profitable, for electricity inflation 2 or $3 \%$. In the case of electricity inflation $1 \%$, none case is profitable.

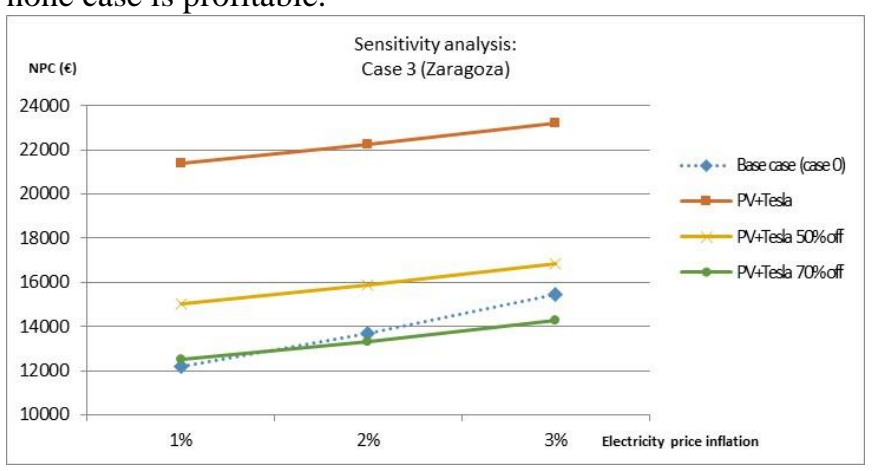

Fig. 6. Results of case 3. NPC vs electricity price inflation.

Fig. 7 shows the simulation of a specific case (PV generation in yellow).

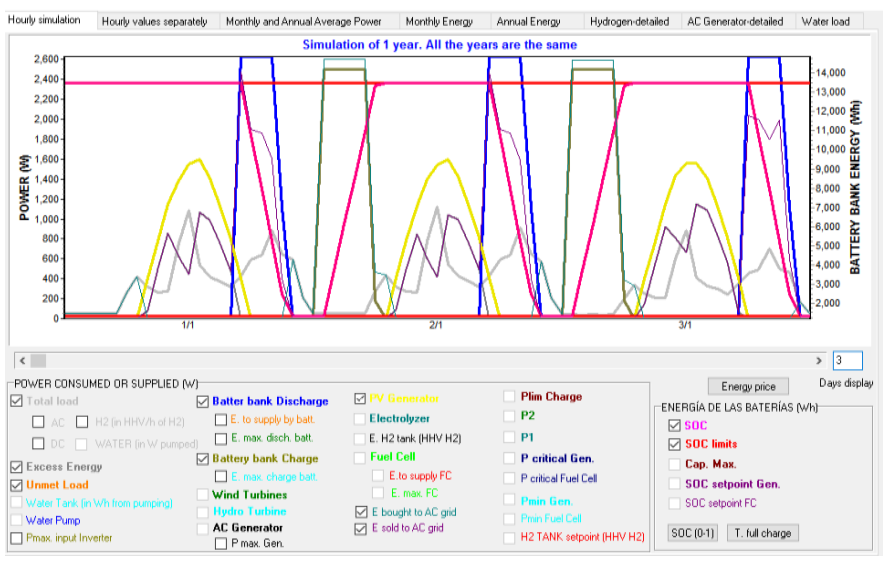

Fig. 7. Simulation of a specific case with PV generator and batteries.

\section{E. Case 4}

If the batteries can sell energy to the AC grid during peak hours, at a price of 30,50 or $70 \%$ of the electricity cost at peak hours, the PV-battery system can be profitable in some cases.

Fig. 8 shows the results of case 4 for a location of Zaragoza, Spain. The subcases include the price discount for the batteries and also the selling price of the electricity (as in case 2). If the battery discount is $70 \%$ the system is profitable for the cases of electricity selling price 50 or $70 \%$ of the electricity tariff.

The case of $70 \%$ battery off and price of selling electricity $70 \%$ of the peak price has a good profitability, with a NPC around $50 \%$ of the base case. 


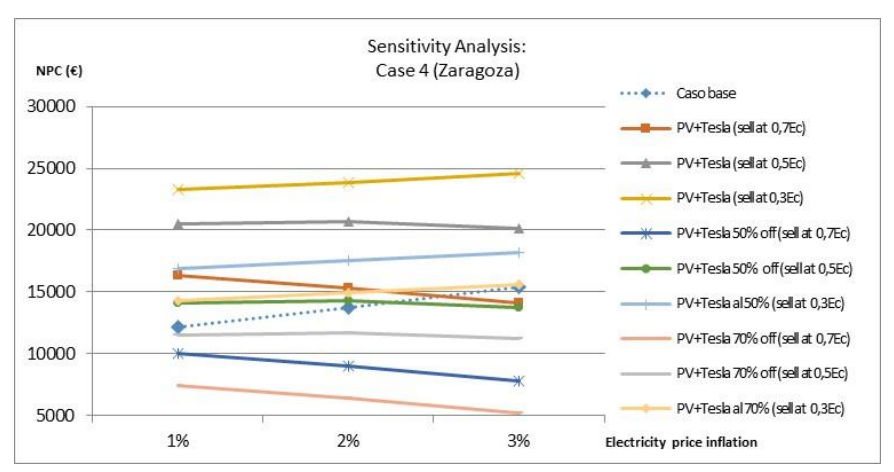

Fig. 8. Results of case 4 . NPC vs electricity price inflation.

\section{Conclusion}

With present prices of batteries and even with the best tariff in Spain (high difference between prices at peak and valley), grid-connected battery systems are not profitable compared to systems without batteries (normal connexion of consumers to the AC grid). The Li-ion battery cost must be reduced at least $70 \%$ to be profitable in this applications.

In that case ( $70 \%$ off in the price of the battery), if selling electricity to the AC grid is allowed and the selling price is $70 \%$ of the price of the peak price of the "Supervalley" Spanish tariff, the battery system can be a good option with good profitability, better with PV generator.

\section{References}

[1] R. Dufo-Lopez, J.L. Bernal-Agustin. Techno-economic analysis of grid-connected battery storage. Energy Conversion and Management. 91 (2015) 394-404.

doi:10.1016/j.enconman.2014.12.038.

[2] https://www.solarquotes.com.au/battery-storage/comparisontable/.

[3] R. Dufo-Lopez. Optimisation of size and control of gridconnected storage under real time electricity pricing conditions. Appl. Energy 144 (2015) 395-408.

doi:10.1016/j.apenergy.2014.12.012

[4] iHOGA software: https://ihoga-software.com/en/

[5] Sofía Sanz Ortega. Análisis de posibilidades de suministro eléctrico mediante baterías de litio conectadas a la red. TFG Ingeniería en Tecnologías Industriales. Universidad de Zaragoza. 2017

[6] Encuesta de Presupuestos Familiares de 2015, del Instituto Nacional de Estadística INE. 